\title{
Dynamic Softening Mechanisms and Microstructure Evolution of TB18 Titanium Alloy during Uniaxial Hot Deformation
}

\author{
Qiang Fu ${ }^{1}$, Wuhua Yuan ${ }^{1, *}$ and Wei Xiang ${ }^{2}$ \\ 1 College of Materials Science and Engineering, Hunan University, Changsha 410082, China; \\ fuqianghnu@163.com \\ 2 Deyang Wanhang Die Forging Co., Ltd., China National Erzhong Group Co., Deyang 618013, China; \\ xiangwei03300121@163.com \\ * Correspondence: yuan731115@hnu.edu.cn
}

Citation: Fu, Q.; Yuan, W.; Xiang, W. Dynamic Softening Mechanisms and Microstructure Evolution of TB18 Titanium Alloy during Uniaxial Hot Deformation. Metals 2021, 11, 789. https://doi.org/10.3390/met11050789

Academic Editor: Frank Czerwinski

Received: 16 April 2021

Accepted: 11 May 2021

Published: 13 May 2021

Publisher's Note: MDPI stays neutral with regard to jurisdictional claims in published maps and institutional affiliations.

Copyright: (c) 2021 by the authors. Licensee MDPI, Basel, Switzerland. This article is an open access article distributed under the terms and conditions of the Creative Commons Attribution (CC BY) license (https:// creativecommons.org/licenses/by/ $4.0 /)$.

\begin{abstract}
In this study, isothermal compression tests of TB18 titanium alloy were conducted using a Gleeble 3800 thermomechanical simulator for temperatures ranging from 650 to $880{ }^{\circ} \mathrm{C}$ and strain rates ranging from 0.001 to $10 \mathrm{~s}^{-1}$, with a constant height reduction of $60 \%$, to investigate the dynamic softening mechanisms and hot workability of TB18 alloy. The results showed that the flow stress significantly decreased with an increasing deformation temperature and decreasing strain rate, which was affected by the competition between work hardening and dynamic softening. The hyperbolic sine Arrhenius-type constitutive equation was established, and the deformation activation energy was calculated to be $303.91 \mathrm{~kJ} \cdot \mathrm{mol}^{-1}$ in the $(\alpha+\beta)$ phase zone and $212.813 \mathrm{~kJ} \cdot \mathrm{mol}^{-1}$ in the $\beta$ phase zone. The processing map constructed at a true strain of 0.9 exhibited stability and instability regions under the tested deformation conditions. The microstructure characteristics demonstrated that in the stability region, the dominant restoration and flow-softening mechanisms were the dynamic recovery of $\beta$ phase and dynamic globularization of $\alpha$ grains below transus temperature, as well as the dynamic recovery and continuous dynamic recrystallization of $\beta$ grains above transus temperature. In the instability region, the dynamic softening mechanism was flow localization in the form of a shear band and a deformation band caused by adiabatic heating.
\end{abstract}

Keywords: TB18 titanium alloy; dynamic softening mechanism; dynamic recovery; dynamic recrystallization; dynamic globularization

\section{Introduction}

Titanium alloys are preeminent candidates for aerospace applications due to their outstanding comprehensive properties, such as high strength-to-weight ratio, excellent corrosion resistance, significant fracture toughness, and reasonable ductility [1-3]. The addition of $\alpha$ phase stabilizing elements, such as aluminum ( $\mathrm{Al})$, and $\beta$ phase stabilizing elements - for instance, vanadium (V), molybdenum (Mo), and chromium ( $\mathrm{Cr}$ ) — gives the alloy good properties but results in a relatively narrow processing window, which is significantly detrimental to its industrial applications. In this situation, thermomechanical processing is usually adopted to improve the hot workability of titanium alloys, which has been successfully applied to fabricate complicated aerospace components, such as landing gear [4], fuselages, and wings [5].

It is well known that the hot workability of titanium alloy is influenced by the initial microstructure characteristics and the hot processing parameters, such as the deformation temperature, strain rate, and strain [6-8], which determine the final mechanical properties by controlling the microstructures. Although numerous studies have been conducted to identify the relationships among process parameters, microstructures, and mechanical properties, to satisfy the different requirements in industrial production, flow-softening behavior is a typical characteristic that has received close attention. In titanium alloys, dynamic softening is usually related to dynamic globularization (DG) [9,10], dynamic 
recovery (DRV) [11,12], dynamic recrystallization (DRX) [13], and flow localization [14,15]. In general, there are three types of DRX during deformation [16]: discontinuous dynamic recrystallization (DDRX), continuous dynamic recrystallization (CDRX), and geometric dynamic recrystallization (GDRX). DDRX occurs when new grains nucleate at grain boundaries through bulging followed by growing at the cost of areas full of dislocations. Meanwhile, when low-angle grain boundaries (LAGBs) are transformed to high-angle grain boundaries (HAGBs) as the deformation proceeds without nucleation and growth process, it is regarded as CDRX. In addition, at elevated temperatures with large strains, when the deformed grains elongate until their thickness bellows to the size of one to two subgrains and serrated grain boundaries pinch off the drenched grains to form equiaxed grains, this process is known as GDRX. Flow localization $[17,18]$ acts as another type of flow-softening behavior at lower temperature and higher strain and includes deformation heat, shear band, material damage, etc.

Many studies have been conducted on the dynamic softening of titanium alloys. Long [19] investigated the hot deformation behavior of Ti-6Cr-5Mo-5V-4Al alloy and found that DRX and DG occurred predominantly in the $(\alpha+\beta)$ phase zone, while DRV occurred primarily in the $\beta$ phase zone. Martina et al. [11] considered that the predominantly hot deformation mechanism of the $\beta$ phase in Ti-55531 alloy was DRV that controlled by subgrain formation. However, it was noted that GDRX occurred along the $\beta$ grain boundaries in Ti-55531 alloy under conditions of large deformation, high temperature, and low strain rates. Tan et al. [20] identified the optimum processing window for Ti-20Zr6.5Al-4V with different strains and deformation temperatures. Wang et al. [12] studied the high-temperature deformation behavior of TB17 titanium alloy. Their results showed that the strain rate sensitivity exponent $m$ remained constant in the $(\alpha+\beta)$ phase zone while it significantly increased in the $\beta$ phase zone. Meanwhile, the optimized process parameters were obtained with a deformation temperature of $885^{\circ} \mathrm{C}$, strain rate of $0.001 \mathrm{~s}^{-1}$, and height reduction of $70 \%$. Wang [21] found that increases in plastic deformation strain, deformation temperature, and strain rate contributed to the DRX behavior of Ti-6.5Al-3.5Mo-1.5Zr-0.3Si alloy in the $\beta$ forging process by finite element method modeling.

Near- $\beta$ titanium alloys with a high content of $\beta$-stabilizing elements showed a relatively lower $\beta$ transus temperature and obtained a microstructure of near-full $\beta$ phase after quenching to an ambient temperature. These alloys are the preferred materials for aerospace component design. In order to meet the various requirements of structural design and material selection for aircraft parts with higher performance, a novel near- $\beta$ titanium, named TB18 alloy, has recently been developed. This alloy exhibited good comprehensive properties after solution and aging heat treatment, i.e., the ultimate tensile strength was above $1300 \mathrm{MPa}$, the total elongation was no less than $5 \%$, and the plane fracture toughness was above $60 \mathrm{MPa} \mathrm{m}^{1 / 2}$; because of its excellent combination of high strength and high fracture toughness, it has great potential to be applied in the aerospace field. However, there are few studies on this novel titanium alloy, and therefore there is a lack of information on hot workability and the dynamic softening mechanisms, which limits its further application.

In this study, isothermal compression tests were conducted under different deformation conditions; then, the flow stress-strain curves, constitutive equation, and processing map were built to characterize the hot workability of TB18 alloy as well as different examinations were performed, such as optical microscopy (OM), X-ray diffraction (XRD), scanning electron microscope (SEM), electron backscattered diffraction (EBSD), and transmission electron microscope (TEM) to identify microstructure characteristics and dynamic softening mechanisms. The results of this study should provide guidance for the production and application of TB18 alloy.

\section{Materials and Methods}

The chemical composition of TB18 titanium alloy (wt.\%) used in the present study was $4.3 \mathrm{Al}, 4.62 \mathrm{Mo}, 4.9 \mathrm{~V}, 5.95 \mathrm{Cr}, 0.95 \mathrm{Nb}, 0.24 \mathrm{Fe}, 0.01 \mathrm{C}, 0.002 \mathrm{H}, 0.11 \mathrm{O}, 0.01 \mathrm{~N}$, with 
the balance Ti. The $\beta$ transus temperature $(\alpha+\beta \rightarrow \cdot \beta)$ was $795-800{ }^{\circ} \mathrm{C}$, determined by the metallographic method. The as-received billet was a forged bar, and the microstructure mainly consisted of equiaxed $\alpha$ phase located inside the $\beta$ matrix, as well as continuous and discontinuous $\alpha$ phase along prior $\beta$ grain boundaries, as shown in Figure 1a. In addition, a rod-like $\alpha$ phase (red arrow) can be observed with an aspect ratio larger than $2 \sim 3$. Figure $1 b$ shows the constituent phases identified by the XRD patterns. The material contained 3 phases, including $\alpha, \alpha^{\prime \prime}$, and $\beta$ phases. The a" martensite phase was transformed from the hightemperature $\beta$ phase during rapid cooling. Due to the lower content of the $\alpha$ phase, it was difficult to calculate the volume fraction from the XRD patterns.
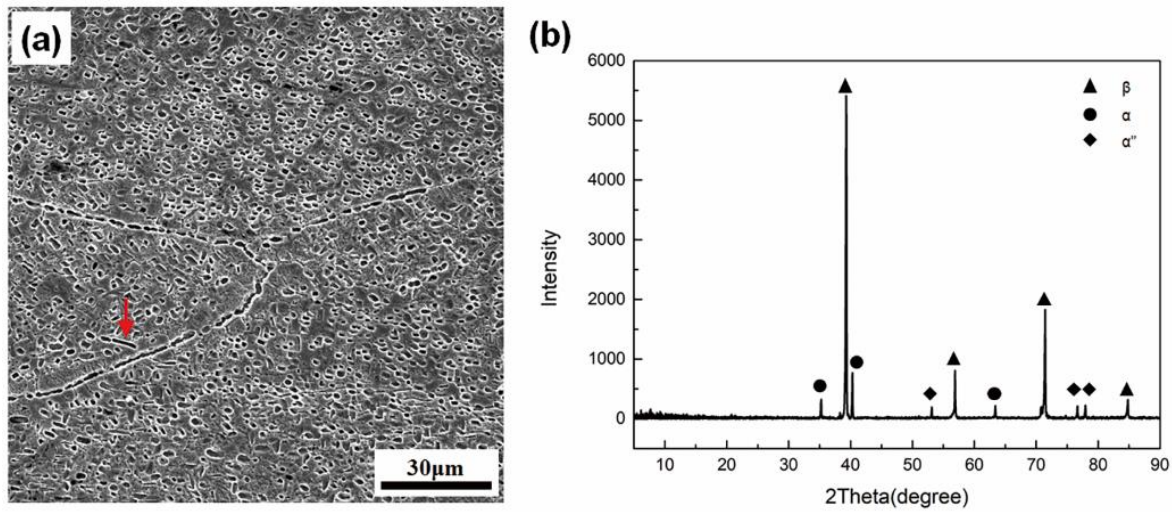

Figure 1. Microstructure of the as-received billet: (a) SEM image; (b) XRD pattens.

Hot compression tests were conducted using a Gleeble 3800 thermomechanical simulator. Cylindrical samples, with a dimension of $\varphi 10 \times 15 \mathrm{~mm}$, were cut from the middle of the billet in the longitudinal direction. Thermocouples were spot-welded at the middle of the samples to measure the temperature change during the deformation process. The samples were heated to deformation temperatures of $650,700,750,800,820,850$, and $880{ }^{\circ} \mathrm{C}$ with a heating rate of $5{ }^{\circ} \mathrm{C} / \mathrm{s}$, followed by isothermal holding for $3 \mathrm{~min}$. Subsequently, the samples were compressed with strain rates of $0.001,0.01,0.1,1$, and $10 \mathrm{~s}^{-1}$, respectively. The height reduction of different samples was constant at about $60 \%$ (the true strain was about 0.92). Finally, the samples were water quenched to room temperature to preserve the deformation microstructure at high temperatures.

The deformed samples were sectioned parallel to the compression axis and the center part of each section was subjected to OM, XRD, SEM, EBSD, and TEM. First, the OM samples were ground and polished, followed by etching using Kroll's reagent (10 vol.\% $\mathrm{HF}, 30$ vol. $\% \mathrm{HNO}_{3}$, and 60 vol. \% $\mathrm{H}_{2} \mathrm{O}$ ). Optical microstructure analyses were performed on a ZEISS-AX10 optical microscope (ZEISS, Oberkochen, Germany). The XRD analysis was performed using a Bruker D8 Discover X-ray diffractometer (Bruker, Karlsruhe, Germany) with $\mathrm{Cu}$ Ka radiation operated at $40 \mathrm{kV}$ and $40 \mathrm{~mA}$. JADE 6.5 software (Material Data Inc., Livermore, CA, USA) was used to analyze the phase structure. The SEM observations were conducted on a Phenom Pro machine (FEI, Hillsboro, OR, USA). The characterization of EBSD samples was performed using an Oxford Nordlys Nano machine (Oxford Instruments, Oxford, UK) after grinding with diamond paste and ion etching using a Leica RES101 ion etcher machine (Leica Microsystems, Wetzlar, Germany). The scan step was $6 \mu \mathrm{m}$. The scanning data were post-processed by HKL CHANNEL5 software (Oxford Instruments, Oxford, UK). The boundaries with misorientation between 2 and $15^{\circ}$ were defined as LAGBs, and those with misorientations larger than $15^{\circ}$ were defined as HAGBs [22]. The TEM examination was carried out on an FEI Talos F200X transmission electron microscope (FEI, Hillsboro, OR, USA). 


\section{Results and Discussion}

\subsection{True Stress-Strain Curves}

In order to eliminate the influence of friction between samples and anvils and the influence of adiabatic heating at high strain rates on flow stress, the measured true stressstrain curves were revised; the details can be seen in our previous work [23]. The corrected flow stress-strain curves under different conditions are shown in Figure 2. The variation of true stress-strain curves elucidated that flow stress was sensitive to the changes of strain rate and deformation temperature, whilst the extent of strain had a significant effect on flow stress, which means that flow stress decreased with increasing strain.

(a)

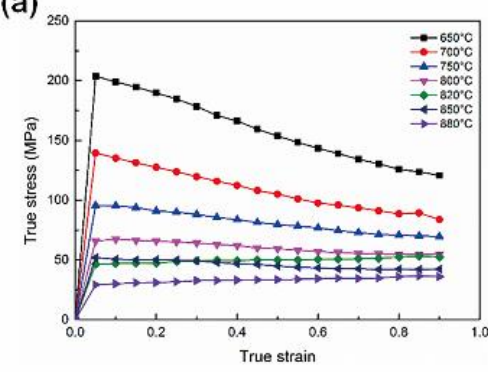

(d) (b)

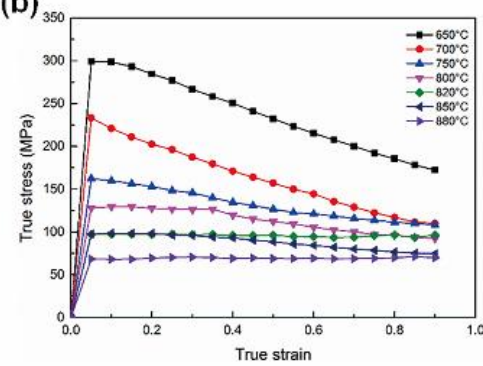

(c)

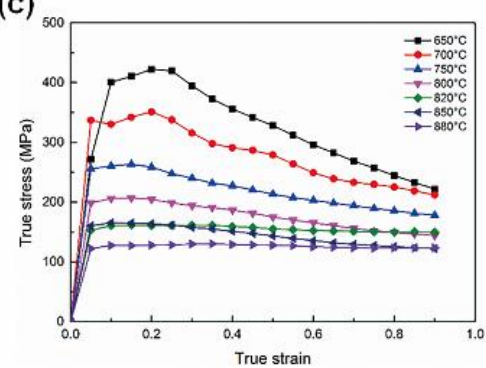

(e)
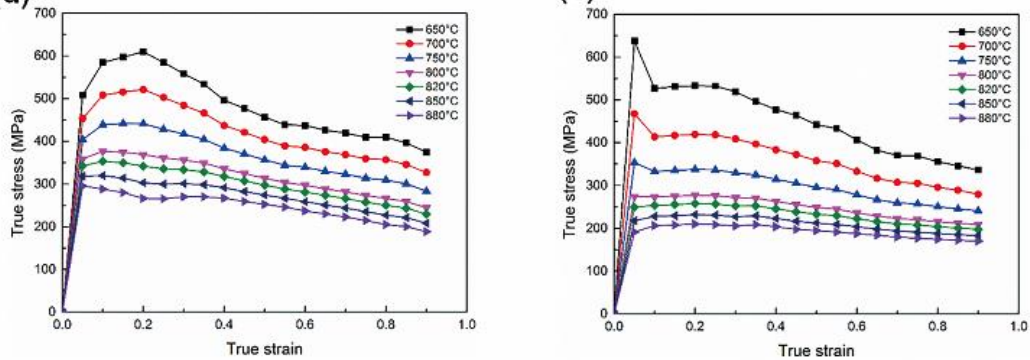

Figure 2. True stress-strain curves of TB18 alloy at (a) $0.001 \mathrm{~s}^{-1}$, (b) $0.01 \mathrm{~s}^{-1}$, (c) $0.1 \mathrm{~s}^{-1}$, (d) $1 \mathrm{~s}^{-1}$, (e) $10 \mathrm{~s}^{-1}$.

At the beginning of the deformation, the fast multiplication of dislocation resulted in a significant increase in flow stress until peak stress, when work hardening (WH) dominated the deformation process. As the deformation proceeded, flow stress decreased with an increase in the deformation temperature or a decrease in the strain rate; flow softening such as DRX occurred in order to decrease the dislocation density and offset the effect of WH. The flow stress-strain curves decreased due to the competition between WH and flow softening. At this stage, flow softening dominated the deformation process. Finally, the flow curves tended to reach a steady state, reflecting a balance between $\mathrm{WH}$ and flow softening. In such a case, the rate of dislocation multiplication was the same as the rate of dislocation annihilation.

The factors that affect flow stress-strain curves are complex. As can be seen in Figure 2, the continuous descending of flow stress-strain curves implied that the underlying mechanism of DRX could be CDRX of the $\beta$ phase [24,25]. Meanwhile, DG of the $\alpha$ phase in the $(\alpha+\beta)$ phase zone and the deformation heat at a higher strain rate also caused flow softening to influence the flow stress-strain curves [26,27]. It is worthwhile noting that at higher temperatures and lower strain rates, the flow stress-strain curves reached a steady state quickly after peak stress, which is a typical characteristic of DRV [28].

In addition, a discontinuous yielding phenomenon was also observed at a strain rate of $1 \mathrm{~s}^{-1}$, which was probably related to the motion and rapid multiplication of mobile dislocations located in the grain boundaries [29]. 


\subsection{Arrhenius-Type Constitutive Equation}

The Arrhenius-type constitutive equation is commonly used to depict the relationships among deformation temperature, strain rate $(\dot{\varepsilon})$, and flow stress $(\sigma)$, which can be expressed as follows [30,31]:

$$
\begin{gathered}
\dot{\varepsilon}=A_{1} \sigma^{n_{1}} \exp \left(-\frac{Q}{R T}\right) ; \text { when } \alpha \sigma<0.8 \\
\dot{\varepsilon}=A_{2} \exp (\beta \sigma) \exp \left(-\frac{Q}{R T}\right) ; \text { when } \alpha \sigma>1.2 \\
\dot{\varepsilon}=A[\sinh (\alpha \sigma)]^{n} \exp \left(-\frac{Q}{R T}\right) ; \text { for all } \sigma
\end{gathered}
$$

where $A, A_{1}, A_{2}, \alpha$, and $\beta$ are material constants, $n$ and $n_{1}$ are the stress exponents, $\alpha=\beta / n_{1}, Q$ is the apparent activation energy $(\mathrm{kJ} / \mathrm{mol}), R$ is the universal gas constant $\left(8.314 \mathrm{~J} \mathrm{~mol}^{-1} \mathrm{~K}^{-1}\right)$, and $T$ is the absolute temperature of deformation $(\mathrm{K})$.

Taking the natural logarithms and partial derivatives successively from both sides of Equations (1)-(3) gives:

$$
\begin{aligned}
& n_{1}=\frac{\partial \ln \dot{\varepsilon}}{\partial \ln \sigma} \\
& \beta=\frac{\partial \ln \dot{\varepsilon}}{\partial \sigma}
\end{aligned}
$$

At a given temperature $T$ and strain rate $\dot{\varepsilon}$, the following equations can be obtained:

$$
\begin{gathered}
n=\left.\frac{\partial \ln \dot{\varepsilon}}{\partial \ln [\sinh (\alpha \sigma)]}\right|_{T} \\
k=\left.\frac{\partial \ln [\sinh (\alpha \sigma)}{\partial(1 / T)}\right|_{\dot{\varepsilon}}
\end{gathered}
$$

Then, $Q$ can be derived from the Arrhenius hyperbolic sine function:

$$
Q=\mathrm{nRk}=\mathrm{R}\left\{\frac{\partial \ln \dot{\varepsilon}}{\partial \ln [\sinh (\alpha \sigma)]}\right\}_{\mathrm{T}} \cdot\left\{\frac{\partial \ln [\sinh (\alpha \sigma)]}{\partial(1 / \mathrm{T})}\right\}_{\dot{\varepsilon}}
$$

The deformation activation energy for TB18 alloy is calculated by $303.91 \mathrm{~kJ} \cdot \mathrm{mol}^{-1}$ in the $(\alpha+\beta)$ phase zone and $212.813 \mathrm{~kJ} \cdot \mathrm{mol}^{-1}$ in the $\beta$ phase zone. Table 1 lists the deformation activation energy of some other near- $\beta$ titanium alloys. The results indicate that TB18 alloy had greater deformation activation energy in both the $(\alpha+\beta)$ phase zone and the $\beta$ phase zone. The deformation activation energy was the basis of studying the deformation mechanism in the process of thermal deformation. By comparing the deformation activation energy with the self-diffusion activation energy, the dynamic softening behavior in hot deformation could be identified [32,33]. The deformation activation energy in the $\beta$ phase zone of TB18 alloy was close to the self-diffusion of pure beta-titanium (135-153 kJ/mol) [34,35], suggesting the dominant deformation mechanism was DRV.

Table 1. Deformation activation energy of near- $\beta$ titanium alloys $\left(\mathrm{kJ} \cdot \mathrm{mol}^{-1}\right)$.

\begin{tabular}{cccc}
\hline & $(\boldsymbol{\alpha}+\boldsymbol{\beta})$ Phase Zone & $\boldsymbol{\beta}$ Phase Zone & Ref. \\
\hline Ti-6554 & 316.864 & 203.157 & {$[19]$} \\
Ti-7333 & 333.74 & 213.83 & {$[36]$} \\
Ti-55531 & 226 & 204 & {$[11]$} \\
Ti-1300 & 275.3 & 148 & {$[13]$} \\
Ti-55511 & 216 & 178 & {$[15]$} \\
Ti-1023 & 550 & 155 & {$[37]$} \\
\hline
\end{tabular}


Moreover, the constitution equations were expressed as follows:

In the $(\alpha+\beta)$ phase zone:

$$
\dot{\varepsilon}=\mathrm{e}^{34.05878}[\sinh (0.00334 \sigma)]^{5.07382} \exp \left(-\frac{303910}{R T}\right)
$$

In the $\beta$ phase zone:

$$
\dot{\varepsilon}=\mathrm{e}^{24.56946}[\sinh (0.00695 \sigma)]^{3.4842} \exp \left(-\frac{212813}{R T}\right)
$$

\subsection{Processing Maps}

The dynamic materials model (DMM) was first proposed by Prasad [38] in 1984. According to this theory, the workpiece is considered to be a dissipator of power in the processing system. The total input power $(P)$ can be expressed as follows:

$$
P=G+J=\int_{0}^{\dot{\varepsilon}} \sigma d \dot{\varepsilon}+\int_{0}^{\dot{\varepsilon}} \dot{\varepsilon} d \sigma
$$

where $G$ is the dissipator content, which is related to the power dissipated by plastic work, most of which is converted into heat, and $J$ is the dissipator co-content, which represents the metallurgical mechanisms that occurred dynamically to dissipate power.

The parameter $\eta$, called power dissipation efficiency, reflects the microstructural changes under a certain deformation condition and is given by:

$$
\eta=\frac{J}{J_{\max }}=\frac{2 m}{m+1}
$$

where $m$ is strain rate sensitivity $(m=\partial \ln \sigma / \partial \ln \dot{\varepsilon})$.

According to the principle of the maximum rate of entropy production, the criterion for flow instability is given as follows [39]:

$$
\xi=\frac{\partial \ln \left(\frac{\mathrm{m}}{\mathrm{m}+1}\right)}{\partial \ln \dot{\varepsilon}}+\mathrm{m}<0
$$

where $\xi$ is the plastic flow instability. Flow instability happens when $\xi<0$.

Superimposing the energy dissipation rate $(\eta)$ map and plastic flow instability $(\xi)$ map under different deformations and strain rates results in the DDM hot processing map, which can be used to characterize the plastic deformation ability of materials, optimize the hot working process, and reveals the hot deformation mechanism [40].

Figure 3 shows the hot processing maps of TB18 alloy at true strains of 0.9 under different deformation conditions. The total domain was divided into the stability region $(\xi>0)$ and the instability region $(\xi<0)$, which are displayed by the pink area and the yellow area, respectively. The processing maps reflect that the TB18 alloy is highly sensitive to strain rate and temperature but has little relation to strain. The instability region occurred when the strain rate was above $0.1 \mathrm{~s}^{-1}$ at all deformation temperatures with $\eta$ values below $30 \%$. At a strain rate below $0.1 \mathrm{~s}^{-1}$, higher $\eta$ values between 30 and $50 \%$ demonstrated the stability region. Meanwhile, the $\eta$ value above $\mathrm{T}_{\beta}$ was higher than that below $\mathrm{T}_{\beta}$ in the stability region.

For titanium alloys, the reported optimum power dissipation efficiency is in the range of $35-50 \%$ due to its relatively high stacking fault energy (SFE) [41,42]. This phenomenon is consistent with other near- $\beta$ titanium alloys, such as TB17 [12], Ti-55511 [43], and Ti5553 [44]. The peak $\eta$ value of $41 \%$ appeared at a deformation temperature range of $800-880{ }^{\circ} \mathrm{C}$ with a strain rate of $0.001 \mathrm{~s}^{-1}$, which indicated the occurrence of DRX in this 
region. As the temperature increased, the peak value zone extended to a higher strain rate of $0.01 \mathrm{~s}^{-1}$.

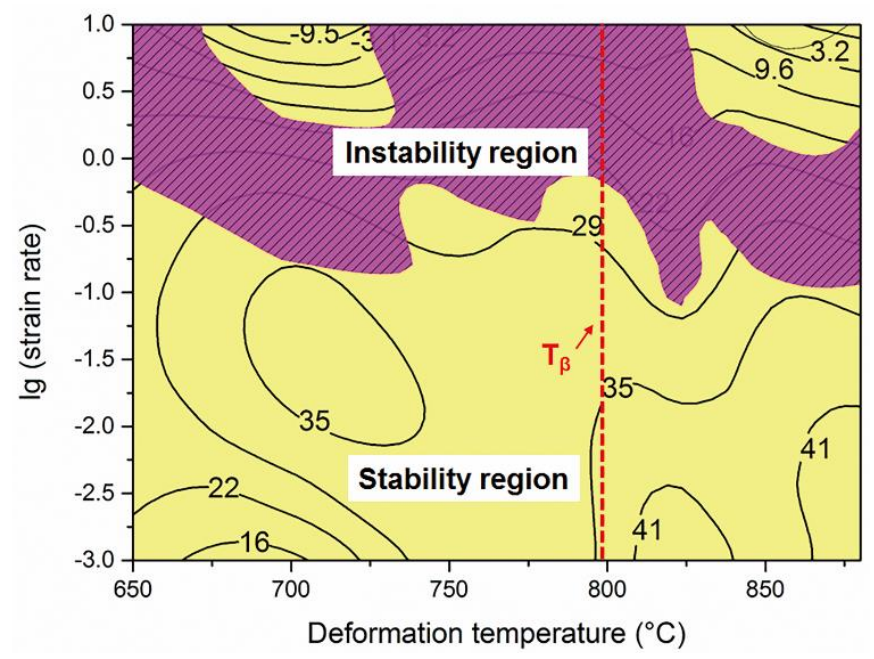

Figure 3. Processing map of TB18 alloy at a true strain of 0.9 .

3.4. Microstructural Characteristics and Restoration Mechanism 3.4.1. Stability Region

(1) Deformation in the $(\alpha+\beta)$ Phase Zone

Figure 4 shows the deformed microstructures in the $(\alpha+\beta)$ phase zone. The microstructures mainly consisted of equiaxial $\alpha$ phase dispersed distributed in the $\beta$ matrix, as well as continuous and discontinuous $\alpha$ phase along the prior $\beta$ grain boundaries, which was similar to the initial microstructure in Figure 1. The elongated $\beta$ grains were observed, which were perpendicular to the compression direction (CD) as shown in Figure $4 a-c$, and no recrystallized $\beta$ grains appeared. This evidenced that the dominant deformation mechanism should be the DRV of the $\beta$ phase in this region. Moreover, the rod-like $\alpha$ phase cannot be seen in Figure 4, and some kinked and split $\alpha$ phase emerged. This suggested the occurrence of DG was the dominant flow-softening mechanism and could be ascribed to one kind of DRX in titanium alloys [14].
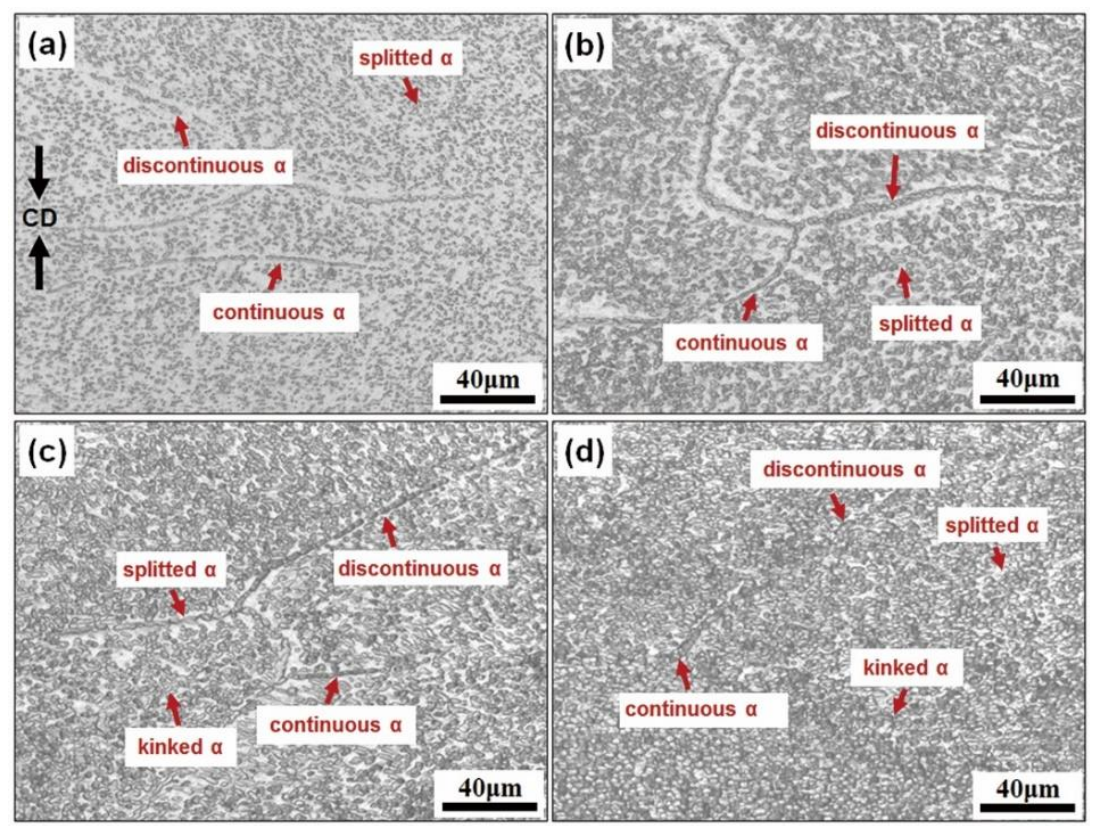

Figure 4. OM images of TB18 alloy deformed in the $(\alpha+\beta)$ phase zone: (a) $700{ }^{\circ} \mathrm{C} / 0.001 \mathrm{~s}^{-1}$, (b) $700{ }^{\circ} \mathrm{C} / 0.01 \mathrm{~s}^{-1}$, (c) $750{ }^{\circ} \mathrm{C} / 0.01 \mathrm{~s}^{-1}$, (d) $750{ }^{\circ} \mathrm{C} / 0.1 \mathrm{~s}^{-1}$. 
Furthermore, TEM observations were performed, as shown in Figure 5. In Figure 5a, a few dislocation lines appear in the $\beta$-phase matrix, as well as some dislocation walls form and aggregate around the $\alpha$ phase. In Figure $5 b$, dislocation piles up near the grain boundaries to form dislocation cells, and dislocation tangles can also be found. In Figure $5 c$, the amount of dislocation can be observed in the $\alpha$ grains, and the $\beta$ phase zone penetrates the rod-like $\alpha$ grains to generate a groove. According to the literature [45-47], the DG process of the $\alpha$ phase can be described as follows: as deformation proceeds, the $\alpha$ phase with HCP structure acting as hard particles impedes the movement of dislocation in the $\beta$ phase and leads to dislocation multiplication in the vicinity and interior of the $\alpha$ phase; the $\alpha$ phase kinks and the $\beta$ phase penetrates into the $\alpha$ phase, and sub-boundaries form; finally, the sub-boundaries transform into grain boundaries and the $\alpha$ phase splits into two equiaxed grains. The incomplete globularization process, shown in Figure $5 c$, also indicates that this process needs sufficient time and higher temperature due to the diffusion-controlled process [48]. This phenomenon has also been reported in another near- $\beta$ titanium alloy [49]. In Figure $5 \mathrm{~d}$, tangled dislocation and dislocation cells appear, and subgrains can also be found. DRV occurs, forming substructures by dislocation glide, climb, or cross-slip due to the high stacking fault energy of titanium alloy, and DRX hardly occurs, which reinforces that the dominant restoration mechanism is DRV.
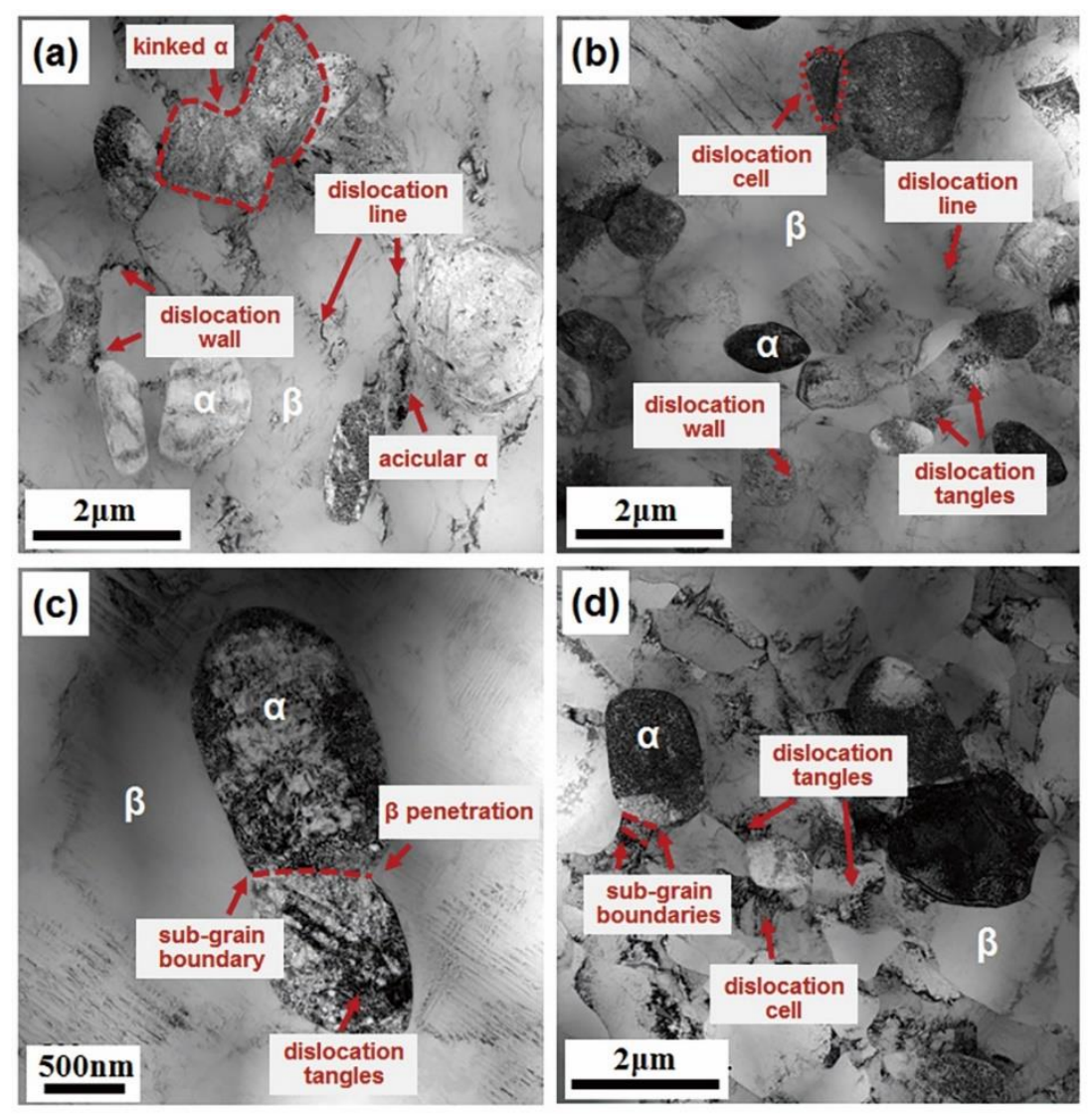

Figure 5. TEM micrographs for TB18 alloy deformed in the $(\alpha+\beta)$ phase zone: (a) $700{ }^{\circ} \mathrm{C} / 0.001 \mathrm{~s}^{-1}$, (b) $700{ }^{\circ} \mathrm{C} / 0.01 \mathrm{~s}^{-1}$, (c) $750{ }^{\circ} \mathrm{C} / 0.01 \mathrm{~s}^{-1}$, (d) $750{ }^{\circ} \mathrm{C} / 0.1 \mathrm{~s}^{-1}$.

Therefore, the dominant restoration mechanism in the stability region below transus temperature was due to DRV of the $\beta$ phase for the following reasons: (1) the $\beta$ grains undergo deformation to elongate perpendicular to the compression direction and no recrystallized $\beta$ grains can be observed; (2) the dislocations are reorganized into cells or subgrain boundaries and developed substructures form; (3) DG of the $\alpha$ phase occurs, and it is eventually incomplete due to sufficient time and higher temperature. Additionally, it 
is worthwhile noting that DG of $\alpha$ grains was the predominant flow-softening mechanism in the $(\alpha+\beta)$ phase zone.

(2) Deformation in the $\beta$ Phase Zone

Figure 6 shows the grain-boundary maps of TB18 alloy deformed in the $\beta$ phase zone. LAGBs and HAGBs are displayed by green and black colored lines, respectively. The contents of HAGB and LAGB are also demonstrated. As shown in the figure, $\beta$ grains distorted perpendicular to the compression direction as the strain rate increased. LAGBs formed in the regions adjacent to the boundary of the grains and tended to decrease from there to the interior grains. This demonstrated that the deformation was concentrated at the grain boundaries and gradually expanded to the grains. As shown in Figure $6 a, b$, the frequencies of LAGBs and HAGBs developed to 57.7 and $39.3 \%$ at a strain rate of $0.001 \mathrm{~s}^{-1}$, and 61.6 and $35.3 \%$ at a strain rate of $0.1 \mathrm{~s}^{-1}$, respectively. As shown in Figure $7 \mathrm{c}, \mathrm{d}$, the contents of LAGBs and HAGBs were 49.2 and $47.8 \%$ at a strain rate of $0.001 \mathrm{~s}^{-1}$ and 59.5 and $37.4 \%$ at a strain rate of $0.1 \mathrm{~s}^{-1}$, respectively. At different strain rates, the frequency of LAGBs ranged from $50-60 \%$, which was twice that of the HAGBs. As the strain rate increased, the content of LAGBs increased. The higher frequency of LAGBs evidenced that the dominant restoration mechanism was DRV of the $\beta$ phase.
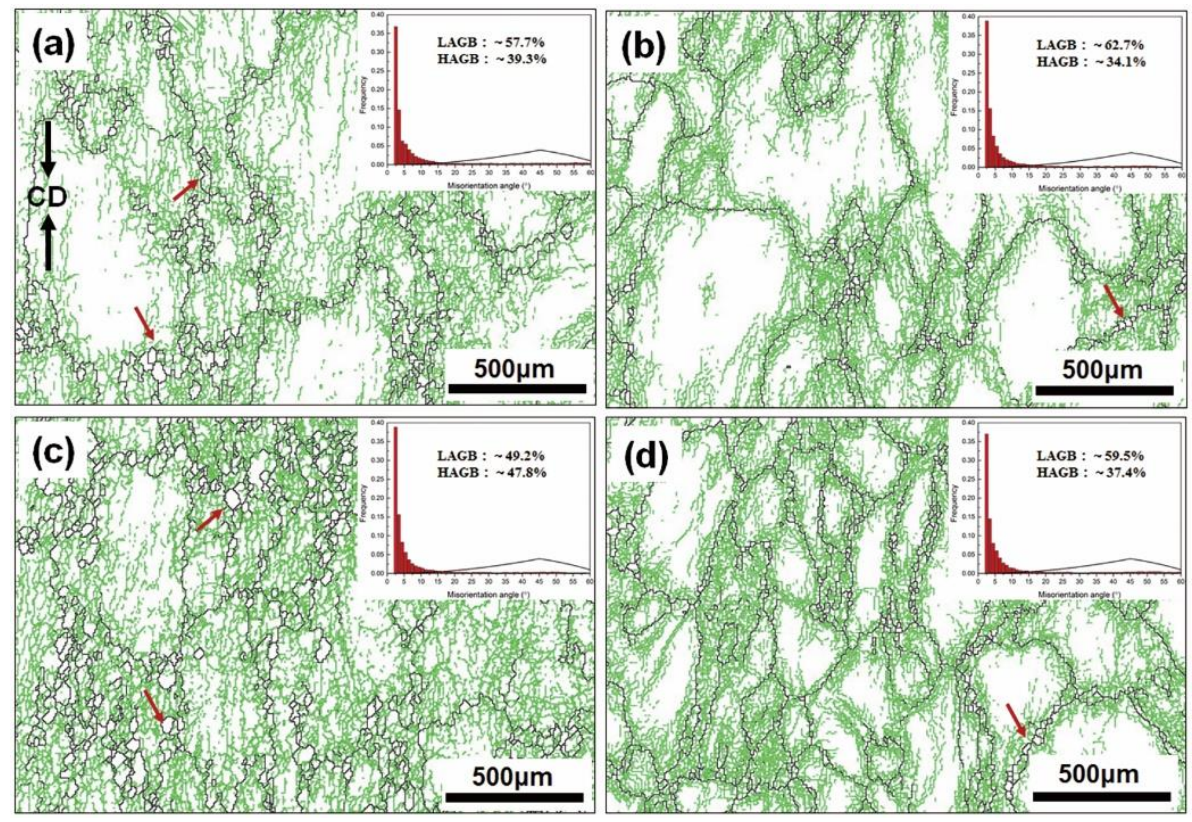

Figure 6. Grain boundary maps of the $\beta$ phase at different deformation conditions: (a) $820^{\circ} \mathrm{C} / 0.001 \mathrm{~s}^{-1}$, (b) $820^{\circ} \mathrm{C} / 0.01 \mathrm{~s}^{-1}$, (c) $850{ }^{\circ} \mathrm{C} / 0.001 \mathrm{~s}^{-1}$, (d) $880{ }^{\circ} \mathrm{C} / 0.1 \mathrm{~s}^{-1}$.

At the beginning of deformation, dislocation was multiplicated along the grain boundaries, then DRV occurred to form LAGBs and the content of LAGBs increased as deformation proceeded. Since DDRX occurred by consuming the deformed substructure containing LAGBs, there was a sharp reduction in the content of LAGBs [50]; therefore, the stable fraction of LAGBs evidenced that DDRX was not the predominant mechanism with these conditions, and CDRX was the dominant softening mechanism. Due to the high stack fault energy of titanium alloy, it requires a relatively higher strain (larger than two) to achieve full dynamic recrystallization [51]. The lower volume fraction of HAGBs indicated that CDRX was in the early stage. As in Figure 6a,c, small recrystallized $\beta$ grains (red arrows) occurred along the grain boundaries and formed a network microstructure, which also proved that the flow-softening mechanism was CDRX. It is important to note that the content of recrystallized grains was lower than 5\%, suggesting that it was not easy for DRX to take place in TB18 alloy and the dominant restoration mechanism was DRV. 

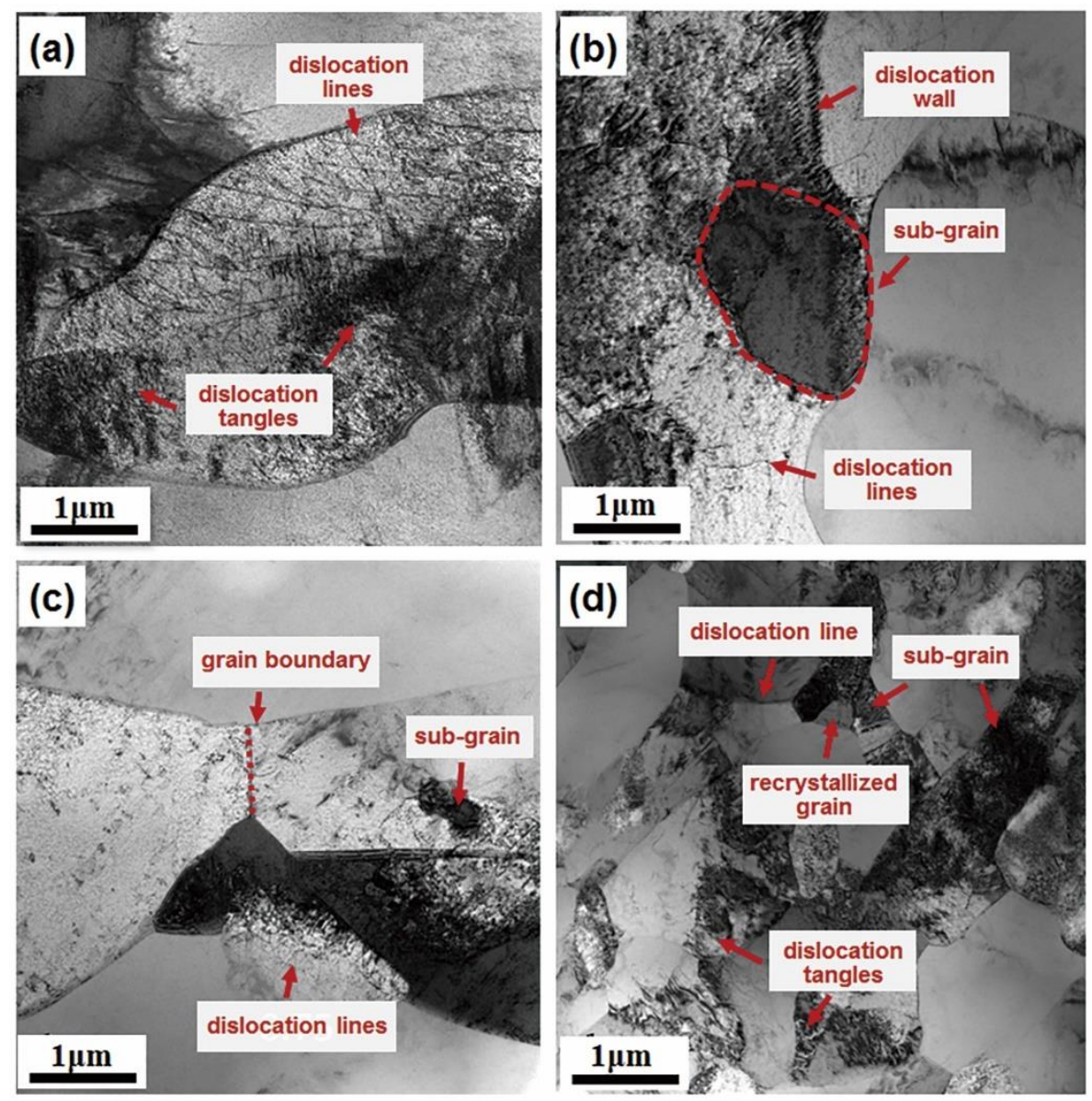

Figure 7. TEM micrographs for TB18 alloy deformed in $\beta$ phase zone: (a) $850{ }^{\circ} \mathrm{C} / 0.001 \mathrm{~s}^{-1}$, (b) $850{ }^{\circ} \mathrm{C} / 0.01 \mathrm{~s}^{-1}$, (c) $880{ }^{\circ} \mathrm{C} / 0.01 \mathrm{~s}^{-1}$, (d) $880{ }^{\circ} \mathrm{C} / 0.1 \mathrm{~s}^{-1}$.

TEM micrographs are illustrated in Figure 7. Lots of substructures can be observed at these deformation conditions. As can be seen in Figure 7a, dislocation tangles formed around the grain boundaries. In Figure $7 \mathrm{~b}$, dislocation walls formed in grains, and subgrains can be seen. Figure 7c shows that the subgrains formed at the trigeminal grain boundary. Numerous substructures can be observed in Figure $7 \mathrm{~d}$ at a higher temperature and strain rate. During the hot compression at strain rates lower than $1 \mathrm{~s}^{-1}$, dislocation generated with deformation proceeded and gathered around the grain boundaries, then tangled dislocation formed dislocation cells and subgrains. No dynamic recrystallization grains can be found except in Figure 7d. It can be concluded that it was difficult for DRX to occur, and DRV was the dominant restoration mechanism in this domain.

In summary, the dominant restoration mechanism in the stability region above transus temperature was DRV of the $\beta$ phase due to the following reasons: (1) the typical DRV characteristic of the flow curves, (2) the deformation activation energy is close to the self-diffusion of pure beta-titanium, (3) a higher frequency of LAGBs, (4) a lower content of recrystallized grains (less than $5 \%$ ), and (5) the formation of developed substructures. In addition, CDRX of the $\beta$ phase was the predominant flow-softening mechanism in this region.

\subsubsection{Instability Region}

Figure 8 shows the optical microstructures of TB18 alloy deformed in the instability region. Two types of flow localization can be observed under the deformation conditions, i.e., shear band and deformation band. Figure 8 a shows the shear band which is $\sim 45^{\circ}$ to the compression direction when deformed at $650{ }^{\circ} \mathrm{C}$ with a strain rate of $10 \mathrm{~s}^{-1}$. This phenomenon has also been observed in Ti-40 alloy [52]. Figure 8b,c shows deformation 
band formation which is almost perpendicular to the compression direction. In Figure $8 \mathrm{~d}$, with a deformation temperature of $850^{\circ} \mathrm{C}$, large $\beta$ grains are elongated under compression in the center of the sample, where strain is concentrated; deformation bands can also be seen in this area. Flow localization was the typical characteristic of plastic instability deformed at a higher strain rate and lower temperature, which has been found in other near- $\beta$ titanium alloys such as TB17 [12], Ti-55531 [11], and Ti-17 [14]. The flow-localization band formed under shear force due to adiabatic temperature rise and low thermal conductivity at lower temperature and higher strain rate [12]. According to our previous work [23], when the strain rate was higher than $1 \mathrm{~s}^{-1}$, the adiabatic heating effect was remarkable, with an increase in strain rate and a decrease in temperature, which potentially affected the actual deformation temperature by almost $90^{\circ} \mathrm{C}$. An increase in temperature resulted in flow softening at high strain rates, while a faster strain rate led to insufficient time for the recovery process [11]. Therefore, the flow stress-strain curves tended to descend, as shown in Figure 2. Hot deformation with high strain rates should be avoided, considering the detrimental effect of flow localization on mechanical properties.
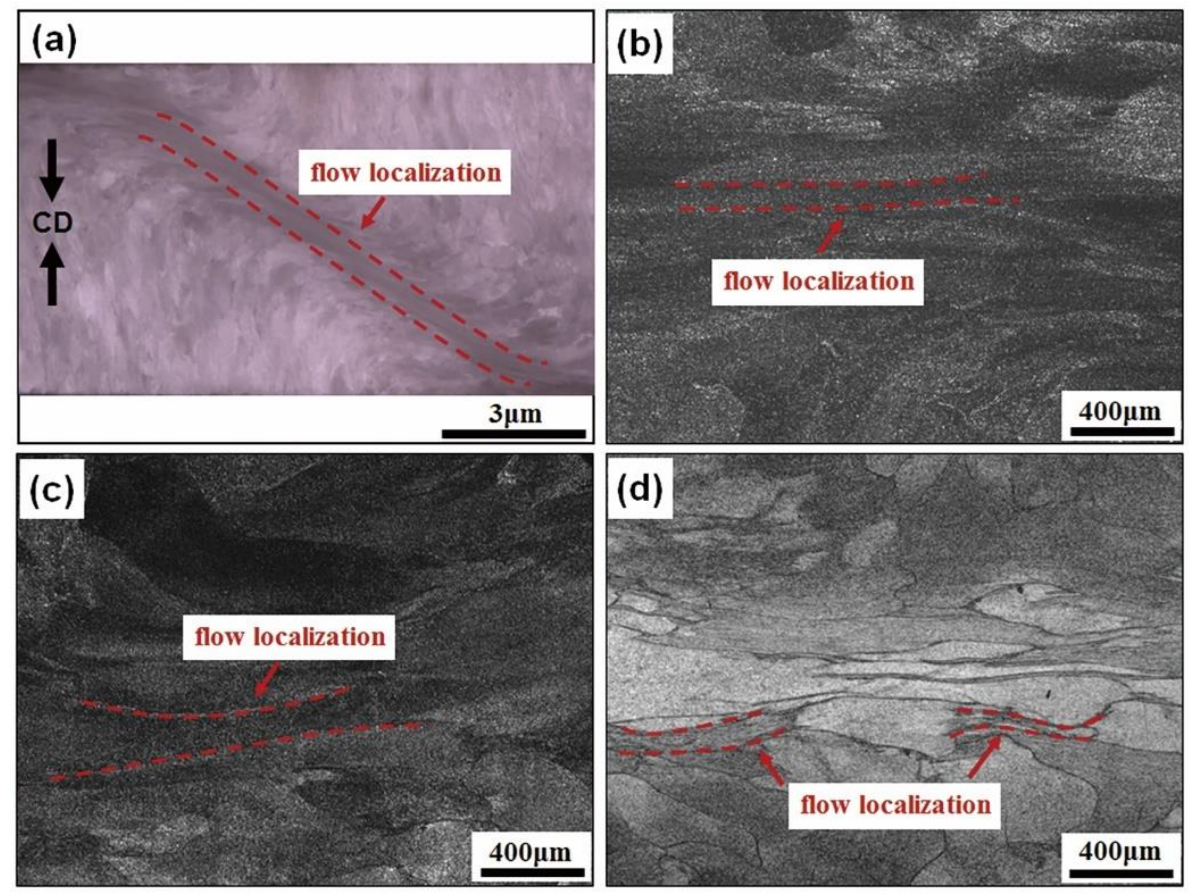

Figure 8. Optical microstructures of TB18 alloy in instability region: (a) $650{ }^{\circ} \mathrm{C} / 10 \mathrm{~s}^{-1}$, (b) $750{ }^{\circ} \mathrm{C} / 1 \mathrm{~s}^{-1}$, (c) $820^{\circ} \mathrm{C} / 10 \mathrm{~s}^{-1}$, (d) $850{ }^{\circ} \mathrm{C} / 1 \mathrm{~s}^{-1}$.

\section{Conclusions}

In the present work, dynamic softening mechanisms and hot workability of TB18 alloy under uniaxial hot compression were investigated under various deformation conditions; the conclusions are as follows:

(1) The flow stress showed high sensitivity to the deformation temperature and strain rate. Work hardening was balanced by the restoration mechanisms after reaching peak stress, and the competition of each other led to the different characteristics of the flow stress-strain curves.

(2) In the stability region, microstructure characteristics and deformation activation energy demonstrated that the dominant restoration and flow-softening mechanisms were the dynamic recovery of $\beta$ phase and dynamic globularization of $\alpha$ grains below transus temperature, as well as the dynamic recovery and continuous dynamic recrystallization of $\beta$ grains above transus temperature.

(3) In the instability region, the dynamic softening mechanism was flow localization caused by adiabatic heating; the shear band occurred at a lower temperature and 
a higher strain rate, whilst the formation of the deformation band occurred at a higher temperature.

Author Contributions: Conceptualization, Q.F.; methodology, Q.F.; validation, W.X.; investigation, W.X.; data curation, W.X.; writing — original draft preparation, Q.F.; writing—review and editing, W.X. and W.Y.; supervision, W.Y. All authors have read and agreed to the published version of the manuscript.

Funding: This research received no external funding.

Data Availability Statement: Not applicable.

Conflicts of Interest: The authors declare no conflict of interest.

\section{References}

1. Boyer, R. An overview on the use of titanium in the aerospace industry. Mater. Sci. Eng. A 1996, 213, 103-114. [CrossRef]

2. Boyer, R.R.; Briggs, R.D. The Use of $\beta$ Titanium Alloys in the Aerospace Industry. J. Mater. Eng. Perform. 2005, 14, 681-685. [CrossRef]

3. Cui, C.; Hu, B.; Zhao, L.; Liu, S. Titanium alloy production technology, market prospects and industry development. Mater. Des. 2011, 32, 1684-1691. [CrossRef]

4. Cotton, J.D.; Briggs, R.D.; Boyer, R.R.; Tamirisakandala, S.; Russo, P.; Shchetnikov, N.; Fanning, J.C. State of the Art in Beta Titanium Alloys for Airframe Applications. JOM 2015, 67, 1281-1303. [CrossRef]

5. Kar, S.K.; Ghosh, A.; Fulzele, N.; Bhattacharjee, A. Quantitative microstructural characterization of a near beta Ti alloy, Ti-5553 under different processing conditions. Mater. Charact. 2013, 81, 37-48. [CrossRef]

6. Jackson, M.; Jones, N.G.; Dye, D.; Dashwood, R.J. Effect of initial microstructure on plastic flow behaviour during isothermal forging of Ti-10V-2Fe-3Al. Mater. Sci. Eng. A 2009, 501, 248-254. [CrossRef]

7. Luo, J.; Lian, L.; Miaoquan, L. Deformation behavior of Ti-5Al-2Sn-2Zr-4Mo-4Cr alloy with two initial microstructures during hot working. Trans. Nonferrous Met. Soc. China 2016, 26, 414-422. [CrossRef]

8. Ghasemi, E.; Zarei-Hanzaki, A.; Farabi, E.; Tesař, K.; Jäger, A.; Rezaee, M. Flow softening and dynamic recrystallization behavior of BT9 titanium alloy: A study using process map development. J. Alloy. Compd. 2017, 695, 1706-1718. [CrossRef]

9. Shell, E.B.; Semiatin, S.L. Effect of initial microstructure on plastic flow and dynamic globularization during hot working of Ti-6Al-4V. Met. Mater. Trans. A 1999, 30, 3219-3229. [CrossRef]

10. Song, H.-W.; Zhang, S.-H.; Cheng, M. Dynamic globularization kinetics during hot working of a two phase titanium alloy with a colony alpha microstructure. J. Alloy. Compd. 2009, 480, 922-927. [CrossRef]

11. Dikovits, M.; Poletti, C.; Warchomicka, F. Deformation Mechanisms in the Near- $\beta$ Titanium Alloy Ti-55531. Met. Mater. Trans. A 2014, 45, 1586-1596. [CrossRef]

12. Wang, Z.; Wang, X.; Zhu, Z. Characterization of high-temperature deformation behavior and processing map of TB17 titanium alloy. J. Alloy. Compd. 2017, 692, 149-154. [CrossRef]

13. Warchomicka, F.; Poletti, C.; Stockinger, M. Study of the hot deformation behaviour in Ti-5Al-5Mo-5V-3Cr-1Zr. Mater. Sci. Eng. A 2011, 528, 8277-8285. [CrossRef]

14. Li, L.; Li, M.Q.; Luo, J. Flow softening mechanism of Ti-5Al-2Sn-2Zr-4Mo-4Cr with different initial microstructures at elevated temperature deformation. Mater. Sci. Eng. A 2015, 628, 11-20. [CrossRef]

15. Zhao, H.; Xiao, L.; Ge, P.; Sun, J.; Xi, Z. Hot deformation behavior and processing maps of Ti-1300 alloy. Mater. Sci. Eng. A 2014, 604, 111-116. [CrossRef]

16. Huang, K.; Logé, R. A review of dynamic recrystallization phenomena in metallic materials. Mater. Des. 2016, 111, 548-574. [CrossRef]

17. Cowie, J.G.; Tuler, F.R. Flow localization models-A review. Mater. Sci. Eng. 1987, 95, 93-99. [CrossRef]

18. Semiatin, S.; Staker, M.; Jonas, J. Plastic instability and flow localization in shear at high rates of deformation. Acta Met. 1984, 32, 1347-1354. [CrossRef]

19. Long, S.; Xia, Y.-F.; Hu, J.-C.; Zhang, J.-S.; Zhou, J.; Zhang, P.; Cui, M.-L. Hot deformation behavior and microstructure evolution of Ti-6Cr-5Mo-5V-4Al alloy during hot compression. Vacuum 2019, 160, 171-180. [CrossRef]

20. Tan, Y.B.; Duan, J.L.; Yang, L.H.; Liu, W.C.; Zhang, J.W.; Liu, R.P. Hot deformation behavior of Ti-20Zr-6.5Al-4V alloy in the $\alpha+\beta$ and single $\beta$ phase field. Mater. Sci. Eng. A 2014, 609, 226-234. [CrossRef]

21. Wang, K.L.; Fu, M.W.; Lu, S.Q.; Li, X. Study of the dynamic recrystallization of Ti-6.5 Al-3.5 Mo-1.5 Zr-0.3 Si alloy in $\beta$-forging process via Finite Element Method modeling and microstructure characterization. Mater. Des. 2011, 32, 1283-1291. [CrossRef]

22. Fan, X.; Zhang, Y.; Zheng, H.; Zhang, Z.; Gao, P.; Zhan, M. Pre-processing related recrystallization behavior in $\beta$ annealing of a near- $\beta$ Ti-5Al-5Mo-5V-3Cr-1Zr titanium alloy. Mater. Charact. 2018, 137, 151-161. [CrossRef]

23. Fu, Q.; Yuan, W.; Xiang, W. Constitutive Relationship for Hot Deformation of TB18 Titanium Alloy. Adv. Mater. Sci. Eng. 2020, 2020, 1-14. [CrossRef] 
24. Furuhara, T.; Poorganji, B.; Abe, H.; Maki, T. Dynamic recovery and recrystallization in titanium alloys by hot deformation. JOM 2007, 59, 64-67. [CrossRef]

25. Furuhara, T.; Toji, Y.; Abe, H.; Maki, T. Dynamic Recovery and Recrystallization in Beta-Titanium Alloys. Mater. Sci. Forum 2003, 426-432, 655-660. [CrossRef]

26. Miller, R.; Bieler, T.; Semiatin, S. Flow softening during hot working of Ti-6Al-4V with a lamellar colony microstructure. Scr. Mater. 1999, 40, 1387-1393. [CrossRef]

27. Semiatin, S.; Seetharaman, V.; Weiss, I. Flow behavior and globularization kinetics during hot working of Ti-6Al-4V with a colony alpha microstructure. Mater. Sci. Eng. A 1999, 263, 257-271. [CrossRef]

28. Ning, Y.; Luo, X.; Liang, H.; Guo, H.; Zhang, J.; Tan, K. Competition between dynamic recovery and recrystallization during hot deformation for TC18 titanium alloy. Mater. Sci. Eng. A 2015, 635, 77-85. [CrossRef]

29. Johnston, W.G.; Gilman, J.J. Dislocation Velocities, Dislocation Densities, and Plastic Flow in Lithium Fluoride Crystals. J. Appl. Phys. 1959, 30, 129-144. [CrossRef]

30. Liang, X.-P.; Liu, Y.; Li, H.-Z.; Zhou, C.-X.; Xu, G.-F. Constitutive relationship for high temperature deformation of powder metallurgy Ti-47Al-2Cr-2Nb-0.2W alloy. Mater. Des. 2012, 37, 40-47. [CrossRef]

31. McQueen, H.; Ryan, N. Constitutive analysis in hot working. Mater. Sci. Eng. A 2002, 322, 43-63. [CrossRef]

32. Galindo-Nava, E.; Rivera-Díaz-Del-Castillo, P. A thermostatistical theory of low and high temperature deformation in metals. Mater. Sci. Eng. A 2012, 543, 110-116. [CrossRef]

33. Shi, C.; Mao, W.; Chen, X.-G. Evolution of activation energy during hot deformation of AA7150 aluminum alloy. Mater. Sci. Eng. A 2013, 571, 83-91. [CrossRef]

34. Ning, Y.; Xie, B.; Liang, H.; Li, H.; Yang, X.; Guo, H.Z. Dynamic softening behavior of TC18 titanium alloy during hot deformation. Mater. Des. 2015, 71, 68-77. [CrossRef]

35. Zhao, J.; Zhong, J.; Yan, F.; Chai, F.; Dargusch, M. Deformation behaviour and mechanisms during hot compression at supertransus temperatures in Ti-10V-2Fe-3Al. J. Alloy. Compd. 2017, 710, 616-627. [CrossRef]

36. Fan, J.; Kou, H.; Lai, M.; Tang, B.; Chang, H.; Li, J. Characterization of hot deformation behavior of a new near beta titanium alloy: Ti-7333. Mater. Des. 2013, 49, 945-952. [CrossRef]

37. Hu, Z.; Zhou, X.; Nie, X.-A.; Zhao, S.; Liu, H.; Yi, D.; Zhang, X. Finer subgrain microstructure induced by multi-pass compression in $\alpha+\beta$ phase region in a near- $\beta$ Ti-5Al-5Mo-5V-1Cr-1Fe alloy. J. Alloy. Compd. 2019, 788, 136-147. [CrossRef]

38. Prasad, Y.V.R.K.; Gegel, H.L.; Doraivelu, S.M.; Malas, J.C.; Morgan, J.T.; Lark, K.A.; Barker, D.R. Modeling of dynamic material behavior in hot deformation: Forging of Ti-6242. Met. Mater. Trans. A 1984, 15, 1883-1892. [CrossRef]

39. Murty, S.N.; Rao, B.N.; Kashyap, B. Instability criteria for hot deformation of materials. Int. Mater. Rev. 2000, 45, 15-26. [CrossRef]

40. Lei, J.; Zhu, W.; Chen, L.; Sun, Q.; Xiao, L.; Sun, J. Deformation behaviour and microstructural evolution during the hot compression of Ti-5Al4Zr8Mo7V alloy. Mater. Today Commun. 2020, 23, 100873. [CrossRef]

41. Prasad, Y.; Seshacharyulu, T. Processing maps for hot working of titanium alloys. Mater. Sci. Eng. A 1998, 243, 82-88. [CrossRef]

42. Zhao, Q.; Yang, F.; Torrens, R.; Bolzoni, L. Evaluation of the hot workability and deformation mechanisms for a metastable beta titanium alloy prepared from powder. Mater. Charact. 2019, 149, 226-238. [CrossRef]

43. Liu, S.F.; Li, M.Q.; Luo, J.; Yang, Z. Deformation behavior in the isothermal compression of Ti-5Al-5Mo-5V-1Cr-1Fe alloy. Mater. Sci. Eng. A 2014, 589, 15-22. [CrossRef]

44. Matsumoto, H.; Kitamura, M.; Li, Y.; Koizumi, Y.; Chiba, A. Hot forging characteristic of Ti-5Al-5V-5Mo-3Cr alloy with single metastable $\beta$ microstructure. Mater. Sci. Eng. A 2014, 611, 337-344. [CrossRef]

45. Huang, S.; Ma, Y.; Zhang, S.; Youssef, S.S.; Qiu, J.; Wang, H.; Zong, B.Y.; Lei, J.; Yang, R. Nonuniform Recrystallization and Growth Behavior of $\beta$ Grains Dominated by Grain Misorientation and Interfacial Energy in Metastable $\beta$ Titanium Alloy. Met. Mater. Trans. A 2018, 49, 6390-6400. [CrossRef]

46. Lin, Y.; Xiao, Y.-W.; Jiang, Y.-Q.; Pang, G.-D.; Li, H.-B.; Zhang, X.-Y.; Zhou, K.-C. Spheroidization and dynamic recrystallization mechanisms of Ti-55511 alloy with bimodal microstructures during hot compression in $\alpha+\beta$ region. Mater. Sci. Eng. A 2020, 782, 139282. [CrossRef]

47. Zherebtsov, S.; Murzinova, M.; Salishchev, G.; Semiatin, S. Spheroidization of the lamellar microstructure in Ti-6Al-4V alloy during warm deformation and annealing. Acta Mater. 2011, 59, 4138-4150. [CrossRef]

48. Sun, J.; Li, M.; Li, H. Initial flow softening and restoration mechanisms of isothermally compressed Ti-5Al-2Sn-2Zr-4Mo-4Cr with basketweave microstructure. Mater. Sci. Eng. A 2017, 697, 132-140. [CrossRef]

49. Long, S.; Xia, Y.-F.; Wang, P.; Zhou, Y.-T.; Gong-Ye, F.-J.; Zhou, J.; Zhang, J.-S.; Cui, M.-L. Constitutive modelling, dynamic globularization behavior and processing map for Ti-6Cr-5Mo-5V-4Al alloy during hot deformation. J. Alloy. Compd. 2019, 796, 65-76. [CrossRef]

50. Wang, X.; Zhan, M.; Gao, P.; Ma, P.; Yang, K.; Lei, Y.; Li, Z. Deformation mode dependent mechanism and kinetics of dynamic recrystallization in hot working of titanium alloy. Mater. Sci. Eng. A 2020, 772, 138804. [CrossRef]

51. OuYang, D.L.; Fu, M.W.; Lu, S.Q. Study on the dynamic recrystallization behavior of Ti-alloy Ti-10V-2Fe-3V in $\beta$ processing via experiment and simulation. Mater. Sci. Eng. A 2014, 619, 26-34. [CrossRef]

52. Sun, Y.; Zeng, W.; Zhao, Y.; Zhang, X.; Shu, Y.; Zhou, Y. Research on the hot deformation behavior of Ti40 alloy using processing map. Mater. Sci. Eng. A 2011, 528, 1205-1211. [CrossRef] 